\title{
DISTRIBUTION AND ABUNDANCE OF FRESHWATER SNAILS AROUND AN EARTH DAM IN NORTHERN NIGERIA
}

\author{
Musa Dogara ${ }^{1}$, Goni Alhaji², Joshua Balogun ${ }^{1}$, Muhammmad Abubakar ${ }^{1}$, Auwal Barde ${ }^{3}$, \\ Abubakar Surajo ${ }^{1}$, Sulaiman Muhammad ${ }^{1}$, Salwa Shehu ${ }^{1}$, and Usman Mohammed ${ }^{1}$ \\ ${ }^{1}$ Federal University Dutse \\ ${ }^{2}$ Federal Polytechnic damaturu \\ ${ }^{3}$ Abubakar Tafawa Balewa University
}

November 27, 2020

\begin{abstract}
Following a preliminary investigation a study was carried from April to October, 2019 to establish more information on the abundance and distribution of freshwater snails in relation to physiochemical factors of Warwade dam. Four sampling sites; human activity, vegetation cover, lentic and lotic were selected for the study along the bank of the dam. Freshwater snails were collected in each of the four sampling sites using long handled scoop net with mesh $0.2 \mathrm{~mm}$ and hand picking methods. Water samples from the sampling sites were analyzed in the laboratory using standard procedures. A total of 2,027 of fresh water snails belonging to ten species were identified with Bulinus globosus $12(0.6 \%)$ and Lymnaea natalensis $12(0.6 \%)$ having the lowest abundance while Melanoides tuberculata 1553(76.6\%) had the highest. Snail abundance was highest in site characterized by human activities (670) followed by vegetation (482), lotic (442) and lentic (433) waters. Most of the physico-chemical factors measured appeared to favour the growth and survival of fresh water snails. $\mathrm{pH}(\mathrm{p}=0.01)$, water current $(\mathrm{p}=<0.01)$ and magnesium ion concentration $(\mathrm{p}=<0.01)$ varied significantly across the four sites. Only calcium ion concentration was significantly associated with snail abundance $(\mathrm{p}=0.04)$. Snail abundance showed weak positive relationship with water temperature, color, turbidity and concentration of magnesium ion. The dominance of M. tuberculata over all species particularly those of medical and veterinary importance could have positive implication for their control in the dam.
\end{abstract}

\section{DISTRIBUTION AND ABUNDANCE OF FRESHWATER SNAILS AROUND AN EARTH DAM IN NORTHERN NIGERIA}

Musa M. Dogara ${ }^{*}$., Goni K. Alhaji1,2., Joshua B. Balogun ${ }^{1}$., Muhammad M. Abubakaar ${ }^{1}$., Auwal A. Barde $^{3}$., Abubakar R. Surajo ${ }^{1}$., Sulaiman I. Muhammad ${ }^{1}$., Salwa S. Dawaki ${ }^{1}$ and Usman M. Isah ${ }^{1}$

${ }^{1}$ Department of Biological Sciences, Federal University Dutse, P. M. B. 7156, Dutse, Jigawa State, Nigeria

${ }^{2}$ Department of Science Laboratory Technology, School of Science and Technology, Federal Polytechnic Damaturu, P. M. B. 1006, Damaturu, Yobe State, Nigeria

${ }^{3}$ Department of Biological Sciences, Abubakar Tafawa Balewa University, P. M. B. 0248, Bauchi, Bauchi State, Nigeria

Corresspondence: Musa M. Dogara, Department of Biological Sciences, Federal

University Dutse, P. M. B. 7156, Dutse, Jigawa State, Nigeria

mmdogara@yahoo.com and musadogara2013@gmail.com

\section{ABSTRACT}


Following a preliminary investigation a study was carried from April to October, 2019 to establish more information on the abundance and distribution of freshwater snails in relation to physiochemical factors of Warwade dam. Four sampling sites; human activity, vegetation cover, lentic and lotic were selected for the study along the bank of the dam. Freshwater snails were collected in each of the four sampling sites using long handled scoop net with mesh $0.2 \mathrm{~mm}$ and hand picking methods. Water samples from the sampling sites were analyzed in the laboratory using standard procedures. A total of 2,027 of fresh water snails belonging to ten species were identified with Bulinus globosus 12(0.6\%) and Lymnaea natalensis 12(0.6\%) having the lowest abundance while Melanoides tuberculata 1553(76.6\%) had the highest. Snail abundance was highest in site characterized by human activities (670) followed by vegetation (482), lotic (442) and lentic (433) waters. Most of the physico-chemical factors measured appeared to favour the growth and survival of fresh water snails. $p H(p=0.01)$, water current $(p=<0.01)$ and magnesium ion concentration $(p=<0.01)$ varied significantly across the four sites. Only calcium ion concentration was significantly associated with snail abundance $(p=0.04)$. Snail abundance showed weak positive relationship with water temperature, color, turbidity and concentration of magnesium ion. The dominance of $M$. tuberculata over all species particularly those of medical and veterinary importance could have positive implication for their control in the dam.

Keywords: Abundance, Distribution, Fresh Water Snails, Physico-chemical, factors

\subsection{INTRODUCTION}

Freshwater snails are organisms that form an important component of food chain and food web of most freshwater ecosystems. Some of the freshwater snails that inhabit freshwater bodies such as lakes, ponds and dams are known to be of medical and veterinary importance. It is estimated that about 350 species are of medical and veterinary importance. The intermediate hosts of human schistosomes belong to three genera;Biomphalaria, Bulinus and Oncomelania. Bulinus species causes urinary schistosomiasis, Biomphalaria species causes intestinal schistosomiasis and Oncomelania species causes fascioliasis or liver rot in animals (Melo et al. , 2012). The distribution and abundance of freshwater snail populations are influenced by temperature, food supply, predators, parasites, rainfall and water composition. Sunlight, flowering aquatic weeds, abundance of micro-flora and high dissolved oxygen also contribute to the abundance of freshwater snails (Hosea et al., 1998). Snail abundance, distribution and density vary significantly with season (WHO, 1993). Biotic factors such as availability and density of aquatic macrophytes have also been reported to play vital roles in the distribution of freshwater snails in different parts of Africa (Ofoezie, 1999).

Physico-chemical factors of the water body that are considered as most important factors in the aquatic environment particularly for freshwater snails are temperature, $\mathrm{pH}$, turbidity, dissolved oxygen, calcium, magnesium and phosphate (Abbasi et al. , 2011). Various physico-chemical and biological circumstances must be simultaneously taken into consideration for understanding fluctuation of biological populations in water body (Dalas, 2004).

Warwade dam, an earth dam is a "weir" constructed in the 1970s solely for the purpose of irrigation is playing a significant role in the socioeconomic activities in the lives of communities sorrounding it, especially Warwade village. Other activities observed by Dogara et al. (2019) at the dam sites include fishing, washing of clothes, swimming and bathing. Since Warwade dam as a "weir" is a typical standing water that is likely to harbour vectors that transmit diseases such as malaria, schistosomiasis and lymphatic filariasis. Reports of surveys from Jigawa State Ministry of Health revealed that the state is endemic for schistosomiasis (Abdurrahaman, 2016). The same report showed that school aged children of Warwade town have a prevalence of $7.1 \%$ for urinary and intestinal schistosomiasis.

The global effort to eliminate schistosomiasis is enshrined in World Health Organization Schistosomiasis plan with a vision of a "World Free of Schistosomiasis" with its end goal to eliminate the disease as a public health problem by 2025 (WHO, 2010). The control of schistosomiasis is based on large-scale treatment of at-risk population groups, access to safe water, improved sanitation, hygiene education, and snail control (WHO, 2020). Snail control is a key component in the global and national programmes for the elimination of schistosomiasis. However, its success largely depends on the understanding of the ecology of freshwater 
snail vectors. Despite the widespread use of earth dams used in irrigation in Nigeria, little is known of the consequences for mollusks of medical or veterinary importance, and hence for the importance of control. Preliminary study in August, 2018 of freshwater snails of the dam by Dogara et al. (2019) revealed the presence of four species in order of increasing abundance and distribution;Lymnaea natalensis , Bellamya unicolar, Melanoides tuberculata and Bulinus globosus. The physicochemical factors measured includes temperature, conductivity, acidity and alkalinity were found to favour the survival of the freshwater snails. This information is not enough to give a realistic picture that could be used in planning and executing freshwater snails control programme that are known to transmit schistosomiasis in Warwade dam. There is therefore the need to understand how intermediate snail hosts abundance will be affected by seasonal changes which mainly influence the prevailing abiotic and biotic factors of their habitats. Again, the period of highest relative abundance must be known if control measures are to be successfully implemented given that the development of an effective control strategy requires the study of population dynamics of the intermediate hosts and its relation to environmental factors (Hussein, et al., 2011). There is also the need to understand the intra-specific competition between the different freshwater snail species in the dam. This work is aimed at studying the distribution and abundance of the freshwater snails of the dam over a longer period of time in relation to important physicochemical factors that affect them.

\subsection{MATERIALS AND METHODS}

\subsection{Study area}

Warwade dam is situated in Northern Nigeria with coordinates $11^{\circ} 45^{\prime} 0^{\prime \prime}$ North, 9 $9^{\circ} 13^{\prime} 0$ " East. Warwade village where the dam is located is about $15 \mathrm{~km}$ south of Dutse, the capital of Jigawa State (Rilwanu, 2018). Construction of the dam began in 1970 by the administration of Military Governor of old Kano State (comprised of present day Kano and Jigawa States) Police Commissioner Audu Bako and was completed in 1976 by the Military Governor of the old Kano State Colonel Sani Bello. .

Information obtained from the Jigawa State Ministry of Environment on the dam showed that it has a crest height 10 metres, crest length 2780 metres, reservoir of 429.5 metres, reservoir capacity $12.3 \mathrm{~m}^{3}$ and its spill way type is box culvert. The dam is fed with water by three major tributaries coming from Dutse and Tsangaya in Jigawa State and Albasu in Kano State. The relief of the area is flat with little undulation (Ahmed, 2003). The geology of the area is sedimentary formation of the Chad basin (Olofin, 1973). The soil of the area is generally sandy. In terms of groundwater the area is characterized by low surface water and high groundwater. The water table of the area is from $25 \mathrm{~m}$ to $50 \mathrm{~m}$ (Abdulhamid, 2014).

The major purpose for the construction of the dam was to provide water for irrigation to the communities living around it. The dam serves the surrounding communities of Warwade, Sabon Garin Alhaji, Sayasaya, Jidawa, Zowon Hawa and Gatari. Other socioeconomic activities observed by Dogara et al. (2019) includes fishing, provision of drinking water for domestic animals belonging to members of the surrounding communities (especially goats and cattle) and washing of wares and clothes. It also serves as source of drinking water to herds of camels, cattle and goats belonging to pastoralists from different parts of the state and beyond.

\subsection{Survey of freshwater snails in relation to physico-chemical factors}

Four sampling sites were purposely selected along the bank of the dam, site one was selected based on the observed frequency of human activities such as swimming, fishing, farming and washing of clothes, the second on vegetation cover, the third on lentic (flowing water) and the fourth was on lotic (standing water). The coordinates of the sampling sites were human activity N11.44'44.8" E009.13'00.4", vegetation cover N11.44'42.9" E009.13'04.5", lotic N11, 44'54.3" E009.12'44.9" and lentic N11. 44'51.1" E009.12'57.8". Sampling at each station was done within ninety meters along the shoreline and 5 meters in shore.

Each of the four (4) sites was sampled once in a month from April to October, 2019 for the presence of freshwater snails. Sampling of snails were done using long handled steel scoop nets $(0.2 \mathrm{~mm}$ mesh) and those that were attached to objects were collected by hand picking using hand gloves. Fresh water snails collected were kept in labeled perforated/aerated plastic containers and transported to the Biology Laboratory, Federal 
University Dutse. They were sorted and then morphologically identified into their respective species as described by Brown, (1994). The snails were counted to determine the number of each snail species collected per site. The plants associated with the freshwater snails were collected, transported to the Herbarium of Department of Biological Sciences, Federal University Dutse where they were identified using standard key.

Surface water samples for determining physico-chemical factors were collected in $1 \mathrm{~L}$ plastic containers. The physico-chemical factors of surface water measured on the field include temperature measured using ordinary mercury glass thermometer, $\mathrm{pH}$ using $\mathrm{pH}$ meter, current/velocity by means of conductivity meter, turbidity using Secchi disc and depth of water body at a distance of 5 meters in shore by means of a meter rule. Chemical properties such as colour, calcium, magnesium, nitrate and phosphate were determined at Challawa Central Laboratory Kano, Kano State using spectrophotometer DR 3900 model. Determination of Dissolved Oxygen and Total Dissolved Solid were done using multi-parallel equivalent machine, model HM 100.

\subsection{Data analysis}

The mean of freshwater snails from each sampling site was calculated to give months as well as total values. Percentages were used to express frequency of distribution of freshwater snails in respect of species and sampling sites. One-way Analysis of Variance (ANOVA) was calculated to show significant difference between distribution and abundance of the freshwater snails across sampling sites. Similarly, ANOVA was used to show the significant difference between physico-chemical factors and the sampling sites. Pearson's Correlation Coefficient was determined to show the direction (positive or negative) and magnitude (weak, moderate or strong) of the relationship between snail population and physicochemical factors. The level of significance was determined at 5\% (P [?] 0.05) and 95\% confidence limit.

\subsection{Ethical clearance}

This was obtained from Ethics Committee, Federal University Dutse. Permission to conduct the study in Warwade dam was also obtained from Jigawa State Ministries of Environment and Agriculture. The purpose of the study was explained to the village head and ward heads of the community of Warwade village.

\subsection{RESULTS}

\subsection{Distribution and abundance of freshwater snails}

Two thousand and twenty-seven (2,027) freshwater snails were collected from the four sampling sites during the study period. Identification based on shell morphology revealed ten species in order of increasing abundance: Bulimulus tenuissimus (d'Orbigny, 1835) 12(0.6\%),Bulinus globosus (Morelet1886), 12(0.6\%), Monach cantian a (Montagu, 1803) 13(0.6\%), Lymnaea natalensis (Linnaeus, 1758) 14(0.7\%), Gabbiella humerosa (Martens, 1879) 14(0.7\%),Drymaeus multilineatus (Say, 1825) 19(9\%), Lanistes varicus (Morelet, 1860) 22(1.1\%), Cleopatra bulimoide s (Olivier, 1804) 66(3.3\%) Bellamya unicolor (Jousseame, 1886) 302(14.9\%) and Melanoides tuberculata (Muller, 1774) 1,553(76.6\%). M. tuberculata was found to be the most dominant fresh water snail species accounting for $76.6 \%$ of the total collected from the dam, followed by B. unicolor with $14.9 \%$. Both M. tuberculata and B. unicolor accounted for $91.5 \%$ of fresh water snails collected from the dam between April and October 2019. Over the entire malacological study period (April to October, 2019), the highest number of fresh water snails were recorded in the site of human activity (670 snails) followed by 482 from vegetation cover, 442 from lotic water and 433 from lentic water (Table 1).

The mean snail abundance varied significantly across the four sampling sites within the same period and duration of sampling (April to October): $F(3,24)=4.82, P=0.01$. Post-hoc comparison test indicated that there were significantly more fresh water snails at site with human activity $(\mathrm{M}=95.7)$ compared to lentic water $(\mathrm{M}=61.9)$ and lotic water $(\mathrm{M}=63.1)$ of the dam from April to October 2019 (Table 2). However, the mean snail abundance at sites with vegetation cover $(\mathrm{M}=68.9)$ did not significantly differ from either site with human activities, or from lentic or lotic water sites. In the sampling sites, M. tuberculata was the most frequently encountered freshwater snail; $B$. unicolor was the second most dominant species in each site followed by $C$. bulimoide s. 
There was a progressive decrease in number of snails collected in all sites with exception of lotic water where the numbers fluctuated after the first sampling in April. The peak period with the highest number of fresh water snails collected in areas with human activity, vegetation cover and lentic water was the month of August. However, in lotic water site, the highest number of snails was collected in the month of May. On the other hand, the least number of snails collected from sites with human activity, vegetation cover and lentic water was in October, while lotic water site recorded its least number of snails in July. This result suggests that sites with human activity, vegetation cover and lentic water share similar snail distribution dynamics with regards to time/season of the year, as shown in Figure 1.

\subsection{Physico-chemical factors in relation to freshwater snail distribution and abundance}

The physico-chemical factors analyzed included temperature, $\mathrm{pH}$, Total Dissolved Solid (TDS), color, current/velocity, calcium, magnesium, nitrate, phosphate, dissolved oxygen, turbidity and depth. The water temperature ranged between $26.4{ }^{\circ} \mathrm{C}$ and $29.7{ }^{\circ} \mathrm{C}$, with highest water temperature recorded at site with lentic water and the lowest at site with human activity. $\mathrm{pH}$ was lowest at sites with vegetation cover (7.0), and highest at lotic water site (8.1). Concentration of magnesium, and water velocity was lowest at lotic water site and highest at lentic water site, with a range of $1.10 \mathrm{mg} / \mathrm{L}$ to $6.02 \mathrm{mg} / \mathrm{L}$ and $2.12 \mathrm{~m} / \mathrm{s}$ to $3.77 \mathrm{~m} / \mathrm{s}$ respectively. Sites with human activity and lentic water recorded consistently lower values for turbidity, while higher values were associated with sites with vegetation cover and lotic water. However, total dissolved solids, dissolved oxygen levels, color, depth and concentration of calcium, nitrates and phosphate, did not show any remarkable variation between all the sampling sites.

Among the physico-chemical factors measured, $\mathrm{pH}(p=<0.01)$, current velocity $(p=<0.01)$ and magnesium ion content $(p=<0.01)$ varied significantly across the four sampling sites along Warwade dam from April to October 2019 (Table 3). Regarding water $\mathrm{pH}$, the actual difference occurred between areas with vegetation cover $(\mathrm{pH}=7.4)$ and lotic water $(\mathrm{pH}=7.9)$. Also, current velocity at sites with vegetation cover $(2.94$ $\mathrm{m} / \mathrm{s})$ and lotic water $(2.72 \mathrm{~m} / \mathrm{s})$ was significantly lower compared to lentic water $(3.51 \mathrm{~m} / \mathrm{s})$. However, sites with human activities did not have a mean velocity that was significantly different from either site with vegetation cover or from lentic water or lotic water. The concentration of magnesium ion was significantly different among all pair wise comparison: lentic water had a concentration of $4.38 \mathrm{mg} / \mathrm{L}$, vegetation cover $3.36 \mathrm{mg} / \mathrm{L}$, human activity $3.14 \mathrm{mg} / \mathrm{L}$ and lotic water $1.24 \mathrm{mg} / \mathrm{L}$.

Of all the physico-chemical factors measured during the study period, only calcium ion concentration was significantly associated with snail abundance $(P=0.04)$. The relationship between snail abundance and concentration of calcium was found to be strongly negative $(\mathrm{r}=-0.8)$. This implies that increase in relative snail abundance was associated with a corresponding decrease in the mean concentration of calcium ion in the dam. Though not statistically significant, snail abundance showed a positive relationship with water temperature, color, turbidity and concentration of magnesium ion. Physico-chemical factors found to be negatively associated with snail abundance but not statistically significant include $\mathrm{pH}$, velocity, depth, dissolved oxygen levels, and concentration of nitrate and phosphate ions. Total dissolved solids did not show any relationship with freshwater snail abundance in Warwade dam $(\mathrm{r}=-0.02)$, is shown in Table 4 .

\subsection{Plants associated with freshwater snails in Warwade dam}

The plants associated with freshwater snails include Typha grass (Typha latifolia), Water lily (Nymphae species ) and Water lettuce (Pistia species).

\subsection{DISCUSSION}

In this study the most abundant and dominant species was $M$. tuberculata accounting for $76.6 \%$ followed by B. unicolar $14.9 \%$, then C. bulimoides $3.3 \%$ and the least were B. tenuissimus and B. globosus with $0.6 \%$ each. The dominance of $M$. tuberculata in all sampling sites over other species in the water body in Warwade dam did not agree with findings of Dogara et al.(2019) that reported it as the second most abundant and dominant species. However, other works carried out in similar water bodies by Rader et al. (2003), Owojori et al. (2006), Abdulkadiret al. (2017) and Almeida et al. (2018) reported M. tuberculata to be the most 
abundant and dominant species.

The abundance and dominance of $M$. tuberculata in this study compared to other species was quite glaring and B. globosus which was the most dominant had now been pushed to the rear. This could be explained by the fact that $M$. tuberculata unlike other snail species such as B. globosus and L. natalensis, is known to thrive only in standing or slow flowing water bodies (Rader et al., 2003) and that it is an invasive species, which competes well withB. globosus and Biomphalaria species (Alexandre et al., 2005). The relatively high percentage observed of $M$. tuberculata reflect their superior natural adaptation such as the presence of their hard protective shell that can withstand harsh environmental conditions and also protect them against predators and drought (Supian and Ikhwannuddin, 2002 and Sharma et al., 2013).

In this study, it appeared $M$. tuberculata had out competed all the encountered fresh water snail species in Warwade dam. The greater abundance of $M$. tuberculata is due to its capacity to explore different environments and tolerance to limnological variation and different types of substrates (Freitas et al., 1987). M. tuberculata, an invasive species is a great competitor and has successfully reduced populations of species of the genusBiomphalaria, which are intermediate hosts of schistosomiasis (Lima et al., 2013). Perhaps that is why according to Oloyedeet al. (2016 in press) it is now monitored worldwide because of its fast growing distribution and its economic importance. This also gives the basis for the introduction of $M$. tuberculata in areas where schistosomiasis was prevalent in the hopes of reducing populations of vector snails such as B. glabrata and Biomphalaria straminea, and thereby reducing the incidence of the disease(Pointer and Guvard, 1992).

Comparison test indicated that in terms of abundance and distribution there were more freshwater snails at site with human activities when compared to lentic water, lotic water and vegetation cover. The observed trend may be due to decreasing favourable conditions required for the survival of the fresh water snails. Incidentally $M$. tuberculata, B. globosus, B. tenuissimus and Lymnaea natalensis were also the most abundant in the site with most human activities. This is consistent with scientific explanation that vectors as transmitters of diseases position themselves where they are likely to come into contact with their suitable hosts. Moreover, B. globosus and B. tenuissimusthat transmit schistosomiasis were prevalent in the study area. L. natalensis was also collected throughout the months of sampling; its presence is also of great public health importance as is known to transmit F. gigantica or $F$. hepatica that causes fascioliasis or liver rot disease in ruminant.

Fresh water snails' distribution and abundance varied significantly across the four sites within the same period and duration of sampling (April to October, 2019). Freshwater snails were more abundant in the months of July and August with exception of lotic site where the highest number was in the month of May because during raining season the water was contaminated by organic and inorganic substances such as fertilizers from surrounding farmlands, the alkalinity of the water were low and as from September to October the distribution of freshwater snail decline due to low rainfall. The highest abundance of fresh water snails recorded in the month of May, 2019 in the lotic site could be as a result of increase in volume of rain and physico-chemical factors that favour the rapid growth and multiplication of freshwater snails in site. However, the mean snail abundance at sites with vegetation cover $(\mathrm{M}=68.9)$ did not significantly differ from either site with human activities, or from lentic or lotic water sites. This could be attributed to environmental changes especially rainfall and some important physico-chemical factors such as temperature, $\mathrm{pH}$, turbidity and phosphate that are required for the growth and survival of the fresh water snails. Rainfall began to increase from April, peaked in August/September before it ceases at the end of October. The onset of rainfall changes the stability of the dam ecosystem prevalent during the dry season which even destroys some microhabitats of the freshwater snails. However, over time, increase in rainfall washes from surrounding farms and lands organic and inorganic materials that promote the growth, survival and fecundity of freshwater snails thus, leading to a peak population in August except for the lotic site that remained more or less undisturbed by the changes in the volume and intensity of rainfall.

The temperature and $\mathrm{pH}$ ranges recorded were within the limits suitable for the survival of freshwater snails in all the sampling sites. The lower values of turbidity recorded in sites with human activities and lentic 
compared to vegetation cover and lotic might have accounted for the relative freshwater snails' abundance in the different sites. The lack of remarkable variation in all the sampling sites of dissolved solids, dissolved oxygen, colour, depth of the water body, concentration of calcium, nitrates and phosphate goes to explain the relative abundance of freshwater snails in all the sampling sites. Of the twelve physico-chemical factors measured only three; $\mathrm{pH}$, current velocity and magnesium were found to significantly vary across the four sampling sites of the dam. This may be due to relative stability of conditions in the dam ecosystem that favours the survival of freshwater snails. Two factors $\mathrm{pH}$ and current velocity are known to be critical for the existence and survival of freshwater snails, therefore their variation over time appear to account for the difference in distribution and abundance across the four sampling sites. However, both of them were within the limits required for the growth and survival of freshwater snails. The $\mathrm{pH}$ recorded from all the sampling sites was slightly alkaline which favours the existence of freshwater snails. The maximum velocity recorded from all the sampling sites was less than 40cm/s which according to Jones, (1993) is suitable for the survival of freshwater snails. Snail intermediate hosts of schistosoma are intolerant of strong current and are not found in flowing water bodies, they are usually found in areas where the velocity is low (Strong et al., 2008). This explained why their abundance and distribution was low in sites of human activity and lentic. Only calcium was found to be significantly associated with the abundance and distribution of fresh water snails. This is because calcium is an important element required in the formation of freshwater snails.

Literature showed that leaves of floating plants protect snails from bright sunlight and high temperature (Heineman, 2009), thus providing a breeding site for the freshwater snails. Also according to Adewole (2001), oviposition is stimulated by the oxygen produced by the plant. In this study typha grass and other plants around served as an indicator plant for the presence of B. globosus in Warwade dam which is the established intermediate host for the urinary schistosomiasis.

\subsection{CONCLUSION}

This study concludes that the environmental conditions coupled with anthropogenic activities in the dam supports the existence of ten species of freshwater snails with varied abundance and distribution over time across the four sampling sites. The most dominant species was $M$. turbaculata followed by B. unicolar then $C$. bulimuides with $B$. teniussumus and B. globosus having the least distribution and abundance. $M$. tuberculata seemed to have out competed all the other species especially those that are of veterinary and medical importance. In this study, four species encountered;B. globosus, M. tuberculata, B. teniussumus and $L$. natalensis are known to be of medical and veterinary importance.

\section{RECOMMENDATION}

There is the need for study that will continue to monitor the distribution and abundance of freshwater snails of Warwade dam in relation to physico-chemical factors in order to establish precisely the factors that influence the changes in snail population especially with the reference to $M$. tuberculata that is the most abundant and dominant species which seems to out compete all the other species in the water body. The information is required in order to be used in the control of snails that are known to serve as vectors of diseases of medical and veterinary importance.

\section{Acknowledgements}

The authors are grateful to the Jigawa State Ministries of Environment and Agriculture, Dutse for granting permission to conduct the research work, the village and ward heads of Warwade village for providing the logistic support to do the work and of course the research assistants that assisted in the process of sample collection in the field. The management of Federal University Dutse provided most of the reagents and equipment used in data collection. We are grateful to Mr. Gabriel for helping with data analysis and M. I. Auyo for identifying the plants.

\section{Data Availability Statement}

None 


\section{Conflict of Interest}

None

\section{Author Contributions}

MMD, GKA, JBB and MMA conceived and designed the work, GAK, MMD and JBB with help of field assistants did the data collection, GAK identified the snails, GAK wrote the initial draft, MMD, JBB, MMA, AAB, ARS, SIM, SDS and UMI reviewed the manuscript and MMD and SIM cross checked the data analyzed.

\section{Accessibility Statement}

The authors hereby agree to make the data emanating from this research to be available and accessible to researchers, academics, research based institutions as well as other data repository such as Dryad.

\section{References}

Abbasi, I., Charles, H. and Robbert, F. S. (2011). Differentiation ofSchistosoma haematobium from Related Schistosome by PCR Amplying an Inter Repeat Sequence. American Journal of Tropical Medical Hygiene, 79: 590-595.

Abdulhamid, A. (2014). Drainage, hydrology and water resources. Kano Environment Society and Development. In tanko, A. I., and Momale, S. B. (eds): Kano: Adonis and Abbey Publishers Ltd; 21 - 34.

Abdulkadir, F., Maikaje, D. B. and Umar, Y. A. (2017). Ecology and Distribution of Freshwater Snails in Gimbawa Dam, Kaduna State, Nigeria.Nigerian Journal of Chemical Research, Vol. 22, No. 2, 98 - 106.

Abdurrahaman, A. U. (2016). Neglected Tropical Diseases Unit, Department of Public Health, Jigawa State Ministry of Health. Unpublished Data. 2016.

Adewole, S. O. (2001). Schistosomiasis and Schistosoma haematobium Infection Among School Children in Ikere-Ekiti, Ekiti state. African Journal of Science. 3(3): 29-33.

Ahmed, K. (2003). Kano Environment . A publication of Kano Forum.

Alexandre, G., Cesar, L., Pinto, A., Coelho, da Silva; Geórgia, B. E. L; Darcílio F. B. (2005). Habitat preference of freshwater snails in relation to environmental factors and the presence of the competitor snail Melanoides tuberculatus (Müller, 1774). Mem. Inst. Oswaldo Cruz, Vol.100, No.2 Rio de Janeiro.http://dx.doi.org/10.1590/S0074-02762005000200010.

Almeida, P. R. S., Filho, S. L. N.and Viana, G. F. S. (2003).Effects of invasive species snails in continental aquatic bodies of Pernambucano semiarid.ActaLimnologicaBrasiliensia, Vol. 30 , e103 . http://dx.doi.org/10.1590/S2179-975X10616 .

Brown, D. (1994). Freshwater Snails of Africa and Their Medical Importance (2 ${ }^{\text {nd }}$ Edition ). London: Taylor and Francis,pp 609.

Dallas, K.(2004). Use of Bayesian Geostatistical Predict to Estimate LocalVariation in Schistosoma haematabium infection in Western African.Bulletin of the world health organization 87:885-964.

Dogara, M. M., Balogun, J. B., Muhammad, A., Abu, P., Ringim A, S., Zakaria, A. and Bashir, M. M. (2019). Abundance and Distribution of Freshwater Snails in Warwade dam, Dutse Jigawa State Nigeria.Journal of Nigeria Tropical Biology Association, Vol. 3/19 p1-3.

Fazio, M. N. and Farrell, W. G. (2005). American Public Health Association Standard Methods for the Examination of Water and Waste Water19 ${ }^{\text {th }}$ Edition, APHA Washington, D.C.

Freitas, J.R., Bedê, L.C., De marco, P., Rocha, L.A. and Santos, M.B.L.(1987). Population dynamics of aquatic snails in Pampulha Reservoir. Memories of the Oswaldo Cruz Institute , 96(1), 123-125. 
Heineman, D.W. (2009). Importance of the Aquatic weed Ceratophylum to Transmission of Schistosoma haematobium in Lake Volta, Ghana.Bulletin of World Health Organization. 58(5): 791-798.

Hosea, Z. Y, Ogbogu VC, Agbede RIS (1998). Snail distribution and habitat preferences in Zaria area, Nigeria. Paper presented at 22 nd annual conference of The Nigerian Society for Parasitology on the 4 th -7 th Nov., 1998 at the University of Benin, Benin City, Nigeria. p. 33.

Hussein, M.A., Obuid-Allah, A.H., Mahmoud, A.A., Fangary, H. M. (2011). Population dynamics of freshwater snails (Mollusca: Gastropoda) at Qena Governorate, Upper Egypt. Egypt. Acad. J. Biol. Sci. 3 (1), $11-22$.

Lima, L.F.O., Brasil, B.I.A.L. and Martins-Silva, M.J. (2013).Melanoides tuberculata (Müller, 1774): Northeastern dispersal in the São Francisco basin, Brazil. Check List , 9(1), 162-164. http://dx.doi.org/10.15560/9.1.162.

Melo, C. C., Pinheiro, J. and Rodrigues, M. L. (2012). Physiological Changes inBiomphalaria glabrata Caused by Sub-Lethal Concentrations Splendens. Memorias Instituto Oswaldo Cruz, 101: 3-8.

Ofoezie, I. E. (1999). Distribution of freshwater snails in the man-made OyanReservoir, Ogun State, Nigeria.Hydrobiologia , 416: 181-191.

Olofin, E.A. (1987). Some Aspects of Physical Geography of Kano Region and Related Human Responses. Kano: Debis Press.

Oloyede, O. O., Otarigho, B. and Morenikeji, O. (2016). Conditions of Eleyele dam in Ibadan Nigeria inhabited by Melanoides tuberculata. Sustainability of Water Quality and Ecology. In Press.

Owojori, O. J., Asaolu, S.O. and Ofoezie, I.E. (2006). Ecology of Freshwater Snails in Opa Reservoir and Research Farm Ponds at Obafemi Awolowo University Ile-Ife, Nigeria. Journal of Applied Sciences,6(15): 304-315.

Pointier, J. P. and Guyard, A.(1992). Biological control of the snail intermediate hosts of Schistosoma mansoni in Martinique, French West Indies. Trop Med Parasitol 43 : 98-101.

Rader, R, Belk, M and Keleher, M. (2003). The introduction of an invase snail Melanoides tuberculata to spring ecosystems of the Bonneville Basin, Utah. Freshwater Journal of Ecology , 18(4), 647- 657. http://dx.doi.org/10.1080/02705060.2003.9 664007.

Rilwanu, Y. T. (2018). Evaluation of the status of water resources and infrastructure for community and development in Warwade, Dutse, Jigawa State, Nigeria. FUDMA Journal of Sciences, Vol. 2, No. 4, PP. 8 -14 .

Sharma, K. K., Bangotra, K. and Saini, M. (2013). Diversity and distribution of Mollusca in relation to the physico-chemical profile of Gho-Manhasan stream Jammu ( $\mathrm{J}$ and $\mathrm{K})$. International Journal of Biodiversity and Conservation, 5 (4): 240-249.

Strong, E. E., Gargominy, O., Ponder, W. and Bouchet, P. (2011). "Global Diversity of Gastropods in Freshwater." The International Journal of Aquatic Sciences, 595: 149-156.

Supian, Z. and Ikhwannuddin, A. M. (2002). Population dynamics of freshwater Molluscs (Gastropoda: M. tuberculata) in Crocker range park, Sabah. Asean Review of Biodiversity and Environmental Conservation $(A R B E C), 1-9$.

World Health Organization (2020). Schistosomiasis . Geneva: World Health Organization. https://www.who.int/news- room/fact-sheets/detail/schistosomiasis.

World Health Organization (2010). Working to overcome the global impact of NeglectedTropical Diseases: first WHO report on Neglected Tropical Diseases. Geneva: World Health Organization. 
World Health Organization (1993). The control of schistosomiasis. Second report of the WHO Expert Committee. Geneva: WHO Technical Report Series, No. 830.

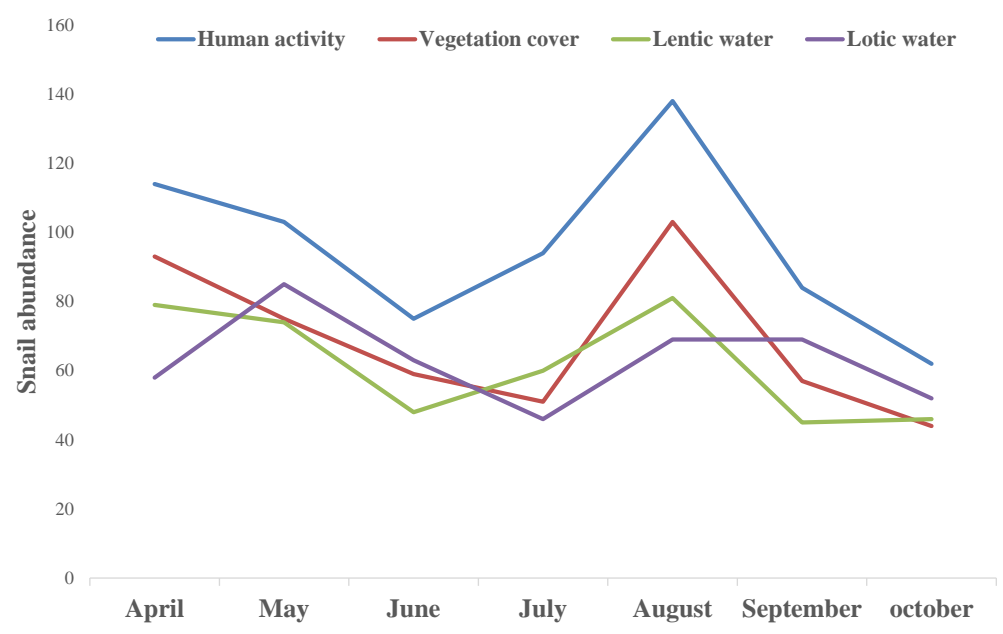

Figure 1: Distribution and abundance of freshwater snails by sampling sites over time in Warwade dam April to October, 2019 